\title{
YOU ARE WHAT YOU DO AND BECOME WHAT YOU'VE DONE: THE ROLE OF ACTIVITY IN DEVELOPMENT OF SELF
}

\section{A Non-Linear Dynamic Systems Relational Approach}

\author{
Karen VanderVen, Professor Emirita, \\ University of Pittsburg
}

With kind permission from Relational Child \& Youth Care Practice: Journal of Child and Youth Care, You are What You Do and Become What You've Done: The Role of Activity in Development of Self. A Non-Linear Dynamic Systems Relational Approach, Vol. 13(2), 1999, 133-147, VanderVen, K., (C) Journal of Child and Youth Care.

\begin{abstract}
The usefulness of professional knowledge is often judged by its ability to bring subjective experience into a comprehensive theoretical framework. In this article, the author uses the broad and rapidly developing parameters of modern systems theory to examine the relationships between "doing" and "being."
\end{abstract}

"Each of our youth has a special activity interest and a hobby," the agency director comments as she leads you into the day room of the group residential home. As you walk in you are stunned. You've never seen such an engaging scene. Several small groups of youth are seated around tables, each one with a worker nearby. One group is playing chess. Another group is working on a quilt, while still another is carefully selecting and gluing tiles onto a mosaic grid. You overhear snatches of conversation, and somehow even the occasional "swear word" seems appropriate for the activities at hand. "S-, man, that was some move you just made!" Looking up for a minute, your eye travels out the window and you see a flash of colour headed for the hoop of a basketball court. Then you hear a whistle: "Coaching instruction for our intramural team," explains the director. You then realize something smells good. "Kitchen detail," she says. "They're interested in cooking and are preparing tonight's snacks."

Contrast the above snapshot-an all too rare occurrence in the world of group care- with the description that follows.

"Each of our youth participates in a weekly self-esteem discussion group that all youth must participate in," the agency director boasts. When you arrive in the day room, however, you are stunned. The wall is dirty and full of holes. Old magazines are strewn around the floor. There is a fleabag of a pool table stuck over in a corner. Looking through a dusty window you notice the grounds with patchy grass, mounds of dirt, and a rusty old basketball hoop without a net. Nobody is at "self-esteem" group — or outside — now. On couches, grimy with years of use, loll the youthful residents, looking scruffy and desultorily glancing at the television set. Inside the staff station, the workers are smoking and writing up their notes. Right now everything is "fine"; the kids are not "acting up" or fighting — although the staff later will tell you this is their main problem with them. 
Many people would see nothing wrong with this latter scenario. But there is; most emphatically so. Why are not the children and youth doing some thing? Something engaging, challenging, productive? Because many of the children and youth in the human service system seem to have problems around relationships, emotions, and interpersonal skills, the focal point of child and youth work practice and professional education has concomitantly encouraged practitioners to handle these areas. The intent of human services to promote positive self-development of clients is continually stressed.

Yet despite this emphasis, there are still scenes like the above-and children and youth whose behavior continues to be unfocused and nonproductive. This hardly contributes to development of self. In biographies and similar other accounts, people have described how their interest in and competence in an activity such as art or sports has contributed to their identity and their sense of having a meaningful place in the world. Successful adults who have written about their experiences"in care" similarly describe the significance of activities in enabling them to develop a strong sense of self, meaningful relationships, and adult success (e.g. Brown, 1983; Seita, Mitchell, \& Tobin, 1996).

Yet, many occurrences in practice directly deprive children and youth of the opportunity to be exposed to and participate in these activities: the use of point and level systems and the current"self-esteem" movement.

Point and level systems are now endemic in many programs serving children and youth. Children and youth must "behave" properly in order to "earn" the" privilege" of participating in activities and, in some settings, even relationships, by "having enough points" to spend time with an adult. These literally deprive children of the major therapeutic and developmental ingredient needed to develop of a strong sense of self, with internal self-regulation, and the skills needed for adult mental health and success (VanderVen, 1995).

The "self-esteem" movement, while already recognized as misguided (Curry \& Johnson, 1990) has made provision of meaningless praise, rather than encouragement of real accomplishment, a common practice. Practitioners are reluctant to provide the activities (that is, if they have"earned" them) that will lead children to a higher standard of performance or skill because this "will lower their self-esteem." Children can spend hours in stupefying, punitive boredom yet be sent to an hour-aweek"self-esteem" group, complete with smiley stickers, in the expectation that this will increase their"self esteem." If we can even accept the developmental utility of the concept of "self-esteem," both the practices of point and level systems and selfesteem groups can be seen as more likely to lower, rather than increase, it; the only true positive evaluation of the self comes through real accomplishment.

Furthermore, these practices fly in the face of contemporary advances in identifying the core purpose and processes of developmental and therapeutic child and youth care work as primarily relational and interactional as embodied in the work of Gerry Fewster (1990), Thomas Garfat (1998), Mark Krueger (1998), and Henry 
Maier (1990). A related, although philosophically somewhat different, stream is the hermeneutic approach to youth work as described seminally by Nakkula and Ravitch (1997). For purposes of this paper, the approach to child and youth practice as collectively embodied by these works will be referred to as"relational child and youth work." Activity is certainly embraced by this body of work, as one of the possible contexts for the interaction and the evolving relationship. Examples in the writings often mention an activity that situated the relationship, for example, the rhythmicity of a game of basketball youth and workers are playing. The possibility exists that articulating more specifically how activities can define, mediate, and enhance relationships and interactions will extend the power of this breakthrough in conceptualizing the distinct nature of child and youth work.

Thus the major premise of this article is that development and reconfiguration of the self of children and youth as focused upon in the new relational model of child and youth care work would be further enriched by the formal inclusion of the concept of "activity" into the approach.

In order to propose such a theory of self-development through activity, it is important to bear in mind contemporary trends in theory construction so that such a theory will have coherence and utility. One major trend is analogical scholarship (Gergen, 1990), in which a paradigm from another field is juxtaposed against the subject field. Non-linear dynamic systems theory, sometimes referred to as, "chaos" or "complexity" theory, originating in the physical sciences, has been applied in recent years to a wide range of social phenomena, on the premise that such an approach can best express their systemic characteristics and enable greater and more realistic insight into productive ways of working with them (e.g. VanderVen, 1997; VanderVen \& Torre, n.d.). In this article, non-linear dynamic systems theory will be applied to construct a beginning outline of a theory of self-development that includes activity as one of the major components of self-development. Included in the paper will be a description of source theories for the theory outline:

- A description of the major tenets of relational child and youth work

- "Activity theory" and its application "activity programming"

- Non-linear dynamic systems theory and specific concepts that can be related to development of self through activity

- The significance of self in personality development of children and youth, how self is developed, and the self as a complex adaptive system

- An outline for a proposed non-linear dynamic systems theory of self in activity as mediated through relational child and youth work, including core principles

- Implications of the theory for child and youth work, most particularly activity programming and relationship-centered practice 


\section{SOURCE THEORIES FOR A THEORY OF SELF DELOPMENT IN ACTIVITY}

\section{Relational Child Care}

The breakthrough work on "relational child care" as already described will serve as the core for integrating self-development, activity theory, and complex adaptive systems theory into an integrated theory of self-development.

Although summarizing can hardly reflect the texture and intricacy of these seminal theories, by viewing them across authors, common threads can be identified:

- The relationship between the child/youth and the worker is the central mediator in that youth's development and is forged in mutuality, rhythmicity, and caregiving interactions

- The process and synchronicity of interaction, focusing more on process than on prescriptive technique, with content of situations being co-determined rather than unilaterally applied from an authority position, is the way in which positive development is encouraged through the relationship that evolves

- Much more so than in other human service professions, the personal selfhood and style of the practitioner is admissible into the relationship, in fact forms its meaningfulness

- The interaction occurs "in the moment" and is multiply determined by personal attributes of the participants and the context (e.g., a caregiving situation, an activity, even a crisis)

- A reconfigured and/or stronger sense of self emerges as the multiplied aspects of the relationship are internalized by the youth and affect his or her ongoing transactions with the environment

With activity integrated into this approach, it is proposed that its ability to promote positive development will be even further enhanced.

\section{ACTIVITY AND ACTIVITY THEORY}

\section{Activity Theory}

Activity theory, as mentioned, is seldom if ever referred to in the "child and youth care" literature, being found, generally, in literature on cultural psychology. This theory is relevant to, and supportive of, the role of activity in child and youth development. Pioneered by the Russian psychologist Leont'ev and drawing heavily on the thinking of Vygotsky, activity theory is now represented by such scholars as Lave and Wenger (1991) and Cole (1996). In general "activity theory" is concerned with how informal learning-particularly skill development-takes place in the 
context of social interaction with others rather than in passive reception of information. It also stresses how the role of the adult is to encourage new learning by providing support to the point that the child finally has mastered the skill and can use it autonomously.

Apprenticeship, for example, is a way of providing "situated learning" through "legitimate peripheral participation" in which knowledge and skills are developed in a cooperative enterprise in context, and result over time in the increased access of learners to participating roles in expert performances until they reach the point of "full participation in the sociocultural practices of a community."Such"participation networks" are structured; in fact they need to be in order to allow peripheral participation to take place (Lave \& Wenger, 1991, p. 17). The concepts of "situated learning" and "legitimate peripheral participation" provide a strong rationale when considering activity and relationships in interaction as crucial in the development of self.

\section{Developmental Aspects of Activity}

Within the child and youth work field the number of writings on activity programming as a function of the practitioner are far fewer in number than those that focus on the relational aspects of child and youth work. Where a rationale for" activity programming" and "activity" is given, it often focuses on the notion of "providing recreation," filling up "free time," or "keeping them (children and youth) busy." There is much less emphasis on how "activity" can promote positive developmental outcomes and, even more so, how "activity" might actually be one of the primary cornerstones of learning, overall development, positive mental health, and successful adulthood.

"Activity" in the context of this paper might be viewed as existing in "domains" of occupations of young people, particularly, but not exclusively, when they are"out of school."Domains of activity include play, sports, games, arts, crafts, service, music, hobbies such as collecting, tricks and rituals of childhood, even entrepreneurship. Traditionally we think of school age and older children as participating in activity and younger children as participating in play, particularly imaginative or "pretend" play. Of course, imaginative play, and certainly the spirit of "playfulness," are not the exclusive domain of preschoolers. The literature on the crucial role of play in development of young children in all spheres - social, emotional, cognitive, and physical — and as an integrator of these capacities is substantial and compelling.

There is much less formal articulation of the developmental benefits of "activity" for older children, especially those in group care settings. Although adults may recognize the need of children and youth to eventually develop vocational and employment maintenance skills, they fail to see the connections between the developmental outcomes encouraged by participation in activities and a developmental process, the growth of activity skills into vocational skills.

However, this author has enumerated these in numerous presentations (e.g., VanderVen, 1981, 1985, 1998). They include promotion of identity, industry, mastery, 
self-regulation and frustration tolerance; physical skill and body image; a wide array of social skills such as empathy, perspective taking, team work, sharing, cooperation; anticipation (time sense); and attending (to name just some of them). Werner and Smith (1992) cited activity, that is, possession of a hobby, as a resilience factor for "at-risk" children. Csikszentmihalyi's (1990) theory of "optimal experience," or flow, relates to activity outcomes, in that "flow" is often attained while deeply involved in a"favorite" activity. Nakkula and Ravitch (1997, p. 249) state that"a childhood ... lacking in the richness of play" (i.e., activity)"compromises opportunities to develop flexible strategies for communication, relationship building, and creativity development."

The significance of self-development through activity is underscored, interestingly, when one views adult development theory, with particular reference to adults (Erikson, 1975) and older adults. With this population, their sense of self is very much determined by their interests, their activities, many of whose origins can be traced in an ever growing trajectory, from childhood. Friedan cites research indicating that older adults who participate in meaningful, substantive activities actually live longer (1992), although for the elderly the nature of these activities and who they do them with is extremely significant in relationship to their having a positive effect.

Certainly, then, there is reason for more concerted attention to articulating the relationship of activity to "self" development in children and youth. Non-linear dynamic systems theory, to be discussed next, provides a cornerstone for seeing how activity participation contributes to the development of a rich and complex"self."

\section{NON-LINEAR DYNAMIC SYSTEMS THEORY AND THE DEVELOPMENT OF SELF}

\section{Non-Linear Dynamic Systems Theory and the Complex Adaptive System}

Non-linear dynamic systems theory is concerned with the behavior of systems which are complex, that is, composed of multiple components that interact with each other in various ways and are open to taking in, and responding to, information from the environment. The process of psychological development, including development of "self" (Butz, 1997), can itself be conceived as a complex adaptive system in which the organism takes in information from the environment, which is mediated through other human beings and the person's own evolving psychic structures. This is then fed back into the structures, continually changing them and therefore the way in which new environmental information is processed. All of this leads to a more complex mental organization and a better ability to relate to challenges in a complex world. Key concepts in non-linear dynamic systems theory that are particularly applicable to developmental processes are connectedness, rescursion, sensitive dependence on initial conditions, attractor, self-organization, far-from-equilibrium, "weak chaos," coupling, entrainment, and emergence. These 
concepts will be central in building a theory of how activity is fundamental in the development of self and will be referred to in the rest of this paper. Table 1 offers a definition of these terms.

\section{The Self as a Complex Adaptive System}

A review of a variety of writings about the nature of "self" yields a number of key attributes that support the contention that the self can be viewed as a complex adaptive system in the context of non-linear dynamic systems theory. The first is that the self has a core, an essential sense of existing and being (using systems language, an attractor) that is maintained even in the face of continued external change. The self is organized and has a pattern as a means of maintaining one's ongoing sense of personal identity, even though that pattern may be constantly shifting. The self has a structure that enables it to entrain new information, yet maintain

\section{Table 1: Key Terms in Complex Adaptive Systems Theory}

Sensitive Dependence on Initial Conditions: A small input into a system can reverberate through it, have multiplicative effects, and yield a large output.

Recursion: A system's output is fed back into the system continuously, thus creating a newer, more complex, and differently behaving system.

Attractor: The governor of a system; the point to which it continually refers back,

Self-organization: The tendency of a loose system to organize itself into patterns.

Far-from-Equilibrium: When a system is continually dynamic, and "off balance."

"Weak Chaos": Making a more static system turbulent and dynamic by "introducing" chaos; this usually means taking some decisive action strong enough to perturb the components of the system.

Coupling: When there is interaction between subcomponents of a system.

Entrainment: When a system co-opts another system which becomes linked to it.

Emergence: An evolutionary-type process in which systems continue to grow and change toward greater complexity and may generate new systems.

this internal sense. The self is complex and dynamic, continually open to new information that it integrates into its current structure, but which alters that structure toward greater complexity and intricacy. The self is actually actively constructed as an individual responds to the messages received and adapts to them in terms of the meaning they have, reflecting the processes of entrainment and recursion."The child is as much an agent of his or her own development as a recipient of the direction of others" (Forman \& Larreamendy-Joerns, 1998, p. 105). This approach to self-construction is very congruent with the concept of constructivist learning as described in Fosnot (1989, pp. 20-21) by VanderVen (1997, p. 45)"in which knowledge consists of past constructions which come from interaction with the environment and the learner's adaptation to new acquired information through a continuous process." 
Thus, the self can be seen as a complex adaptive system: the attractor is the core of self, which provides the basis for continued entrainment of information with the self continuing to emerge in greater complexity over time. That is, the self is involved in an ongoing process of recursive construction-if development proceeds well. That complexity of self is crucial in development is supported by Rescher (1998), who states that the most effectively functioning mental capacities are those that are complex — have the most structures, the most openness to new information.

Thus, the paradox of the self in the developing human being is its stability-it continues as a stable and central personality feature throughout the life span, yet it is constantly undergoing change and modification, behaving very much like a complex adaptive system. It has been obvious, of course, that the "self" and "selfconcept" do not develop in a vacuum. It goes without saying that significant adults play a fundamental role in offering and mediating the experiences that contribute to a child's developing sense of self, first through serving as attachment figures and later, in a multiplicity of teaching, caregiving, coaching and other supportive roles (Curry \& Johnson, 1990) that situate the experiences children have that in turn they use to construct their sense of self. As children become older, the peer group (Selman, Watts, \& Hickey-Schultz, 1997) assumes a central function as a social force affecting the self. The "textures" of these relationships help children assess themselves and their place in the social world; their sense of self then contributes towards determining their"place" in that world in a continuous interactive process.

\section{THE THEORY OF ACTIVITY IN DEVELOPMENT OF SELF IN RELATIONAL CHILD AND YOUTH CARE: A BEGINNING OUTLINE}

Using selected concepts outlined in the preceding discussion of activity theory, complex adaptive systems theory, and development of self, the following outlines the beginnings of a new, integrated theory of activity in development of self in the context of relational child and youth work. The concepts of non-linear dynamic systems theory are used to construct the basic premises of the theory.

Connectedness. Perhaps the central function of activity in self-development and relationship is the fact of connectedness. Presence of an activity-to attract interest or even resistance - enables both parties to connect with each other. Without such a mediator to enable two different"selves" to cross boundaries and engage with each other, such a connection may be less likely to occur, particularly if-as is likely the case with at-risk youth - they have few internal resources and social skills to bring to the transaction. The activity is indeed central in setting the context for "situated learning" and "legitimate peripheral participation."

Attractor. The notion of attractor-the governor of a system-is crucial in the development of self. When there is no structured or focused activity in a setting, there is no external attractor in the system that situates the youth(s) and in that way the following can occur: 
- The youth(s) will be bored and unfocused, and there will be a greater tendency for unproductive and acting-out behavior to occur. This will move the staff toward limiting and punitive responses, thus diminishing the quality of any relationship and interaction that existed.

- A relationship that is not mediated by an activity may move over acceptable boundaries - even with the more flexible boundaries permitted in relationship-centered child care-without a mediating influence, or not be enabled to occur at all.

- An activity initiated or embedded in the context of a setting serves as an attractor in the interactive setting between youth and staff.

This then provides focus for the relationship, its process and content depending on the staff's perception of the youth's readiness for relationship. The activity can be used to allow distancing and neutrality. Often inserting an educational and structural aspect to an activity allows this, that is, giving formal skill instruction and practice enables this to occur until, through the trust that hopefully evolves, more closeness can occur. In this situation, more "selfhood" emerges on the part of the worker, who tempers education with style, which provides greater variety of expression to be internalized by the youth in his or her self-development.

Sensitive dependence on initial conditions. This phenomenon-that a small input may lead to a major outcome in a complex system-supports the concept of utilizing an activity to initiate a relationship. The focus this begins can then iterate over time to become a major attribute of self and lead to very positive outcomes.

A basic example of an entry behavior that can determine the evolution of a relationship and activity interest that can contribute to self-development is a worker who arrives and says, "Hey, I brought my yo-yo today. Used to play with it a lot when I was a kid. Want to try?" Immediately a context to shape and focus the interaction is set. The youth may respond in any number of ways: ignore the worker, walk away, brighten up, or hold out his hand for the yo-yo. But immediately there is something for the worker to respond to, and the dynamic aspect of the interaction is primed. It is even possible that some youth will become truly interested in developing yo-yo skills that can be used to help him engage meaningfully with others and contribute to the growth of an ever more complex and positive selfwith the origins being a very simple initial situation. Imagine the contrast if the worker begins by saying,"You just lost 50 points for not having this place cleaned up."The youth stiffen up with resentment which can similarly reverberate through the context and future interactions - ending up some time later, with angry, unaccomplished, disengaged youth.

Recursion. The notion that information generated as an open system evolves is fed back into that system, spurring it on to greater complexity, is a dynamic that explains paradoxical results in interventions with children and youth, and supports the relationship-centered model, especially as activities are increasingly made part 
of the content of those relationships. When the focal point, or attractor, in the system (context) is control, such as embraced by a point and level system, the more the context emphasizes control, the more resistance develops, resulting in even greater attempts to control and greater resistance, ultimately yielding alienation, anger, and disengagement from relationships and productive interactions.

In child and youth care settings, short-sighted adults attempting to control their youthful clients will either make them "earn" what little activity there is (VanderVen, 1995), by "good" behavior-even when they do not have the skills to attain such a behavioral standard (which might be attained through more unconditional participation in activity)—or will simply not offer sufficient activity, thus compromising the opportunity for them to begin to develop the complexity of personality that will enable them to attain a more positive adulthood. Thus they give way to boredom. Although in some cases boredom may force a child to utilize his or her own resources for stimulation and engagement, thus contributing to development, more likely the individual either gets involved in anti-social or negative behavior or simply settles for an emptier personality akin to his or her daily living situation.

Far-from-equilibrium. Utilizing an activity as the situator of relationships and interactions sets up a situation that is analogous to triangulation in family systems, with the activity being the third point. Without a third entity, two entities can become static, whereas with three there are constant shifts in balance. This encourages the system to be far-from-equilibrium, actually an optimal state, because it can entrain more information and hence grow in complexity. A worker offering an activity to a youth or a group, or vice versa, can encourage a far-fromequilibrium state.

Self-organization. The tendency of a system with even minimal structure embedded in its context does not need a great deal of energy inputted to evolve its own coherent structure and pattern, that is, self-organization. For example, a youth who is introduced to star-gazing by a worker and begins to spend his evenings purposefully doing his homework so there will be time to work on building a telescope with that worker and watching the constellations is exhibiting internal self-organization. The expanded knowledge, connections, and interests that develop represent the ideal complex, coherent, evolving self that will be able to approach new situations with greater complexity.

Weak chaos. Deliberately"stirring up" a system by injecting "weak chaos"—perhaps doing something paradoxical or unexpected-can keep a system "dynamic" and open to change including the evolving self-hood of youth. This is a prime function of the worker in the relationship-centered model, using activities as an extension of himself. Allowing a youth to stay up unusually late, taking him on a challenging trip, shopping for a new piece of equipment, simply adding novelty or surprise to an activity or any number of other actions can restore declining energy, move things in another promising direction. 
Coupling. In self-development, as either an activity or a relationship connection become internalized, the mental subsystems these represent can begin to connect with each other and affect each other transactionally. The activity will change the youth's internal sense of self (toward greater richness and complexity) and conversely, as the sense of self changes, relational capacities will increase.

Entrainment. One of the most exciting aspects of activity occurs when a youth is enabled to establish a new interest, with the support and investment of a worker (which situates the activity and relationship). There is then the potential for this system to relate to other external systems, that is, other domains of activity, related domains of activity. For example, a youth who becomes interested in ceramics might participate in community ceramics activities, meet other ceramicists, write about ceramics, and take up painting and drama as well.

Emergence. Finally, we can consider the concept of emergence in the development of self through activity. As the self as a complex dynamic system evolves both internally and externally, as described above, competencies for living and for relationship building — as mediated by activities—and activity interests and skills—as mediated by relationships in ongoing oscillation-emerge.

\section{Core Principles}

From the above non-linear dynamic systems theory conceptualization of the development of self through activity, I offer the following core principles to specifically guide efforts to enhance use of activity as a child and youth work intervention:

1. Context is crucial in child and youth work and exerts an inexorable influence on interaction and relationships. The context reflects the systemic aspects of person and environmental interaction.

2. Activities can define the nature of the environment and the feedback it gives to the interaction and relationships of participants. The nature of the activity, who introduces it, how it is structured and delivered, the responses of participants-all interactively affect and shape the overall content and pattern of interaction and relationships.

3. When the context is "activity-rich" - that is, there is an activity situating the interactions and relationships-greater complexity and mediation are possible, increasing the possibility that these are developmentally productive. Activities provide more energy, options, and variables for modifying the processes of interactions and relationships. Specific knowledge of activities (e.g., kinds of responses elicited by various media) allows utilization of activities to enhance interaction and relationships.

4. Activities engaged in by children and youth mediate relationships and interaction. Because the activity adds an additional component 
to the interactional system, it encourages greater complexity, thus providing the youth with a greater number of possible pathways to explore in the future and options from which to choose.

5. Activity knowledge and skills directly encourage development of positive self-concept. Activity interests promote and allow the forging of connections, and the opportunity to gain feedback in response to one's offering and sharing of activity knowledge and skills. An individual's own internal awareness of interests and skills increases confidence in initiating and maintaining relationships. The element of complexity thus introduced continues to expand and enhance the self-concept.

\section{IMPLICATIONS FOR CHILD AND YOUTH PRACTICE}

The theory of self-development through activity as situated in relationships and context offered in this paper suggests that not only are relationships enriched when activity is an attractor in the system, but the activity can actually serve to mediate the formation of relationships, especially in at-risk children and youth.

For this premise to be enacted in practice, training and education, and settings, practitioners might consider the following:

\section{Training and Education}

Self-in-reflection. Progressive training and educational programs openly endorse discussions, journals, the concept of the reflective practitioner, and the like that help the developing practitioners recognize their own selfhood as it affects their style: ways of relating to others and applying new information. Activity should be encouraged in contrast to implementation of control strategies such as point and level systems, and the power of activity in constructively modifying behavior, as well as enhancing the relational capacity of both adults and youth, stressed.

Added to these activities might be more emphasis on recollections of play and activity, and the role these played in the development of self, relationships, and one's current life pattern. Similarly, more emphasis on the role of activity in one's adult functioning could be made. These reflections will bring the significance of activity more to the forefront, and make it more accessible for actual use by the practitioner.

Activity theory and activity programming. Training and educational curricula can give appropriate balance and in-depth consideration to activity theory. Although activity theory has been stressed in preparation of European educateurs, it has had little attention in child and youth work. This could be changed, however, as this theory is a crucial component in understanding how self develops in environmental contexts that can be structured to enhance their effectiveness in promoting learning and development. Activity programming, while included in some curricula, might follow the example of European social pedagogue education and bring the theory, practice guidelines, and knowledge of specific domains of activity to the forefront. 
Prospective child and youth workers should be formally prepared in a number of activity areas, and apply them in guided practice.

\section{Practice}

Systemic changes. More activity-centered settings can only be implemented through attention to their systemic aspects. Administrators must recognize how activities not only lead to positive outcomes for children and youth, but also how to support their implementation in the milieu. They must promote throughout the agency a value system that supports activity programming, as well as specific practices. These include actively reducing endorsement of point and level systems, providing adequate and well-maintained equipment and supplies, including activity knowledge and competence in job descriptions and hiring practices, and providing activity-oriented on-the-job training. Supervisors also need to be able to translate these premises into their practices.

Direct changes. Direct line workers need a situation in which ongoing activity, formal and informal, can continually be conducted, and in which their personal interests and competencies can be comfortably entered into practice. They will undoubtedly find that their relationships with youth and youth's relationships with each other are enhanced and their joy in the work increased as they experience the pleasure of youth growing and learning through relationship and activity.

\section{CONCLUSION}

This paper has presented an outline for a non-linear dynamic systems theory of self-development through activity as mediated by relational child and youth work and situated in the contexts in which interactions take place. Whichever is the initiator of these transactions - the activity or the relationship — the fact remains that we are what we do, and what we do is integral to who we are and what we continue to become.

\section{References}

Brown, W. (1983). The other side of delinquency. New Brunswick, NJ: Rutgers University Press.

Butz, M. (1997). Chaos and complexity: Implications for psychological theory and practice. Washington, DC: Taylor and Francis.

Cole, M. (1996). Cultural psychology: A once and future discipline. Cambridge, MA: Harvard University Press.

Csikszentmihalyi, M. (1990). Flow: The psychology of optimal experience. Nonlinear Dynamics, Psychology and Life Sciences, 3(10), 113-118. 
Curry, N., \& Johnson, C. (1990). Beyond self-esteem: Developing a genuine sense of human value. Washington, DC: National Association for the Education of Young Children.

Erikson, J. (1975). Activity, recovery, growth: The communal role of planned activities. New York: WW Norton.

Fewster, G. (1990). Growing together: The personal relationship in child and youth care. In J. Anglin, C. Denholm, R. Ferguson, \& A. Pence (Eds.), Perspectives in professional child and youth care (pp. 25-40). New York: Haworth Press.

Forman, E., \& Larreamendy-Joerns, J. (1998). Making explicit the implicit: Classroom explanations and conversational implications. Mind, Culture \& Activity, 5(2), 105-113.

Fosnot, C. (1989). Enquiring teachers, enquiring learners. New York: Columbia University Teacher's College Press.

Friedan, B. (1992). The fountain of age. New York: Simon \& Schuster.

Garfat, T. (1998). The effective child and youth care intervention: A phenomenological inquiry. Journal of Child and Youth Care, 12(1-2).

Gergen, K. (1990) Social understanding and the inscription of self. In J. Stigler, R. Shweder, \& G. Herdt (Eds.), Cultural psychology: Essays on comparative human development (pp. 569-606). Cambridge: Cambridge University Press.

Krueger, M. (1998). Interactive youth care work. Washington, DC: Child Welfare League of America.

Lave, J., \& Wenger, E. (1991). Situated learning: Legitimate peripheral participation. Cambridge: Cambridge University Press.

Maier, H. (1990). The personal relationship in child and youth care. In J. Anglin, C. Denholm, R. Ferguson, \& A. Pence (Eds.), Perspectives in professional child and youth care (pp. 7-24). New York: Haworth Press.

Nakkula, M., \& Ravitch, S. (1997). Matters of interpretation: Reciprocal transformation in therapeutic and developmental relationships with youth. San Francisco: Jossey-Bass. 
Rescher, N. (1998). Complexity: A philosophical overview. New Brunswick, NJ: Transaction Publishers.

Seita, J., Mitchell, M., \& Tobin, C. (1996). In whose best interest: One child's odyssey, a nation's responsibility. Elizabethtown, PA: Continental Press.

Selman, R., Watts, C., \& Hickey-Schultz, L. (Eds.). (1997). Fostering friendship. New York: Aldine De Gruyter.

VanderVen, K. (1981). Developmental activity programming. In G. Foster, K. VanderVen, N. Carbonara, G. Cohen, \& E. Kroner (Eds.), Child care work with emotionally disturbed children (pp. 203-243). Pittsburgh, PA: University of Pittsburgh Press.

VanderVen, K. (1985). Activity programming: Its developmental and therapeutic role in group care. In L. Fulcher \& F. Ainsworth (Eds.), Group care of children (pp. 15-183),

VanderVen, K. (1995). Point and level systems: Another way to fail children and youth. Child and Youth Care Forum, 24(6), 345-367.

VanderVen, K. (1997). Chaos/complexity theory, constructivism, interdisciplinarity, and early childhood teacher education. Journal of Early Childhood Teacher Education, 18(3), 43-48.

VanderVen, K. (1998). From just keeping them busy to the power of activity programming: Reasons, methods, results. Handout packet for activity programming workshops. Pittsburgh, PA.

VanderVen, K., \& Torre, C. (n.d.). Toward transformed mediation of violence in schools: The contribution of chaos and complexity theory. Unpublished manuscript.

Werner, E., \& Smith, R. (1992). Overcoming the odds: High risk children from birth to adulthood. Ithaca, NY: Cornell University Press. 